\title{
Treatment of nocturnal asthma with nedocromil sodium
}

\author{
Luke Clancy, Sheila Keogan
}

\begin{abstract}
Background - The association of nocturnal asthma symptoms with a diurnal increase in inflammatory activity suggests a role for anti-inflammatory therapy in nocturnal asthma.

Methods - Fifty patients with asthma with nocturnal symptoms entered a randomised, double blind, placebo controlled, crossover study. After a two week baseline period patients received nedocromil sodium (4 mg) or placebo four times daily. After eight weeks of treatment patients crossed to the alternative treatment for a further eight weeks. Symptom severity was recorded on a scale of $0-4$ and inhaled bronchodilator use and peak flow (PEFR) were also recorded daily by the patients. Asthma severity, pulmonary function (FEV, PEFR, FVC), and adverse events were recorded at clinic visits (baseline and after four and eight weeks of treatment). Global effectiveness was rated by clinician and patient, and treatment preference was recorded.
\end{abstract}

Results - Efficacy was assessed from data from 28 patients. Night-time asthma (mean (SE) difference between nedocromil sodium and placebo: $-0.52(0 \cdot 13))$, total nocturnal symptom severity defined as night-time asthma plus morning tightness $(-0.72(0.20))$, and night-time bronchodilator use $(-0.62(0.23))$ were reduced with nedocromil sodium compared with placebo treatment during the primary efficacy period (weeks 5-8) and during weeks $1-4(-0.36(0.12),-0.63(0.20)$, and $-0.55(0.28)$, respectively). Morning and evening PEFR values improved slightly but not significantly - compared with placebo. Patient and clinician opinions favoured nedocromil sodium treatment. Daytime asthma, daytime cough, and clinic assessment of asthma severity (secondary efficacy variables) were improved with nedocromil sodium treatment; daytime bronchodilator use and clinic pulmonary function were not.

St James's Hospital, James's Street, Dublin 8, Ireland L Clancy

S Keogan

Reprints will not be available.

Received 25 November 1992 Returned to authors 9 February 1993

Revised verson received 13 February 1994

Accepted for publication

8 September 1994
Nocturnal symptons are a common problem for asthmatic patients, with more than one third of patients being woken every night. ${ }^{12}$
The frequency of this symptom is unchanged with current treatment, which suggests that improvements could be made. ${ }^{2}$ The efficacy of nedocromil sodium ${ }^{3}$ and the pathophysiological basis ${ }^{14}$ of nocturnal asthma warrant a trial of this anti-inflammatory drug. ${ }^{5}$ We describe a study which specifically addressed the nocturnal aspects of chronic asthma.

\section{Methods}

Patients (minimum age 14 years) with a history of nocturnal asthma symptoms, currently using an inhaled bronchodilator, with $\geqslant 15 \%$ reversibility in forced expiratory volume in one second $\left(\mathrm{FEV}_{1}\right)$ or $\geqslant 15 \%$ diurnal variability in peak expiratory flow (PEFR) during the baseline period and $\mathrm{FEV}_{1}<80 \%$ predicted normal (on entry or during the previous six months) were eligible for this crossover study. A record of an exacerbation of respiratory symptons within six weeks of the study was an exclusion criterion.

After a two week baseline period patients were randomised to receive $4 \mathrm{mg}$ nedocromil sodium or placebo four times daily for eight weeks, followed by eight weeks using the alternative treatment. Other asthma drugs were continued unchanged. Patients who changed their therapy (except inhaled bronchodilators) or reported an exacerbation of respiratory systems were withdrawn. Throughout the study patients recorded symptom severity (night-time asthma, morning tightness, daytime asthma and cough) using a $0-4$ scale $(0=$ no symptons, $1=$ mild, $2=$ moderate, $3=$ severe, or $4=$ very severe), the highest of three measurements of peak expiratory flow using a mini-Wright peak flow meter (on waking, 16.00-18.00 hours, and on going to bed), and medication used on daily diary cards. Patients with a nocturnal symptom score $\geqslant 20$ (night-time asthma plus morning tightness) over seven consecutive baseline days entered the treatment period.

At clinic visits (baseline and after four and eight weeks of treatment) diary cards were checked, asthma severity assessed (as above), the highest of three measurements of $\mathrm{FEV}_{1}$, forced vital capacity (FVC), and PEFR recorded from spirometric measurements, and adverse events noted.

Patients and clinicians rated overall treatment efficacy $(1=$ very effective, $2=$ moderately effective, $3=$ slightly effective, $4=$ no effect, or $5=$ made condition worse) and decided at the end of the study which treatment period was more effective. Patients also selected their preferred treatment (first, second or neither). 
Table 1 Mean (range) patient characteristics

\begin{tabular}{ll}
\hline Age (years) & $41 \cdot 8(15-72)$ \\
Sex $(\mathrm{M} / \mathrm{F})$ & $16 / 12$ \\
Asthma duration (years) & $13 \cdot 2(0 \cdot 5-63)$ \\
Severity (moderate/severe) & $22 / 6$ \\
& \\
Medications & prn \\
Inhaled $\beta_{2}$ bronchodilators $(\mathrm{n}=28)$ & $9 \cdot 7 \mathrm{mg}(6-15)$ \\
Oral $\beta_{2}$ bronchodilators $(\mathrm{n}=3)$ & $644 \mathrm{mg}$ \\
Oral theophyllines $(\mathrm{n}=14)$ & $(225-1000)$ \\
& $719 \mu \mathrm{g}(32-2000)$ \\
Inhaled corticosteroids $(\mathrm{n}=16)$ & $5.2 \mathrm{mg}(5-5 \cdot 4)$ \\
Oral steroids $(\mathrm{n}=2)$ & \\
FEV & \\
$\%$ predicted & $64 \cdot 8(29 \cdot 3-103 \cdot 9)$ \\
$\%$ reversibility $(\mathrm{n}=27)$ & $30 \cdot 3(1 \cdot 3-85 \cdot 7)$ \\
\hline
\end{tabular}

*From the multiple choice question "Severity of asthma in the last 12 months or since diagnosis (whichever is shortest)": mild, moderate, severe, or very severe.

All patients gave written informed consent. The study received hospital ethical review approval.

\section{DATA ANALYSIS}

The primary variables were night-time asthma, morning tightness, nocturnal asthma symptom score (night-time asthma and morning tightness), night-time bronchodilator use, morning and evening PEFR, and patient and clinician opinions. The primary period for the diary card variables was the latter four weeks of treatment (weeks 5-8). All comparisons were between treatments and were made on changes from baseline. Pulmonary function was analysed using repeated measures ANOVA with order group, treatment, and period as factors. All other variables, except preference data (binomial test), were analysed using the Koch method for crossover trials. ${ }^{6}$ Two-tailed tests at the $95 \%$ significance level were used.

Patient data were included wherever possible. Data were included from patients withdrawn because of treatment failure if they had completed at least seven days of the second treatment period. Clinic data were included as an extreme score or opinion, and diary data for that period as the mean of the last three days before withdrawal.

\section{Results}

Twenty five patients were randomised to each group. Twenty three were withdrawn for the following reasons on the following treatments: cough (one, nedocromil sodium); worsening symptoms (two, placebo); exacerbation of respiratory symptoms (eight, placebo; three, nedocromil sodium); non-treatment related reasons (five, placebo; four, nedocromil sodium). Most patients withdrew during or at the end of their first treatment period. One of the two placebo treated patients withdrawn because of worsening symptoms had received treatment for more than seven days. The data were included for this patient. Comparative efficacy was therefore assessed from the crossover analysis of data from 28 patients (table 1).

Significant reductions $(p<0.01)$ in nighttime asthma, nocturnal symptom score, and night-time inhaled bronchodilator use occurred with nedocromil sodium treatment during the primary evaluation period, weeks $5-8$ (table 2 ). The changes in morning tightness and cough failed to reach statistical significance during weeks 5-8. During weeks 1-4 improvements in all diary card symptom scores and in clinician assessment of asthma severity significantly favoured nedocromil sodium $(p<0 \cdot 05)$ (table 2$)$. The mean diary card score for PEFR was not significantly different between nedocromil sodium and placebo, and no significant changes were seen with clinic assessment of pulmonary function or daytime inhaled bronchodilator use (table 2). Both patients $(\mathrm{p}<0.01)$ and clinicians $(p<0.001)$ considered nedocromil sodium very or moderately effective compared with placebo (table 3). The nedocromil sodium treatment period was found to be more effective $(p<0 \cdot 01)$. There was no difference in patient preferred treatment (11, nedocromil sodium; eight, placebo; nine, no preference).

Nine withdrawn patients reported adverse events: seven (five, placebo; two, nedocromil sodium) reported wheeze, chest tightness, cough and sputum, and were among those withdrawn because of an exacerbation of respiratory symptoms; the other two reported

Table 2 Mean (SD) baseline values and mean (SE) difference between nedocromil sodium and placebo

\begin{tabular}{|c|c|c|c|c|c|c|c|c|}
\hline \multirow[b]{2}{*}{ Efficacy variable } & \multicolumn{4}{|c|}{ Baseline values } & \multicolumn{4}{|c|}{ Nedocromil minus placebot } \\
\hline & Weeks 1-4 & & Weeks 5- 8 & & Weeks 1-4 & & Weeks 5-8 & \\
\hline $\begin{array}{l}\text { Symptom scores } \\
\text { Night-time asthma } \\
\text { Morning tightness } \\
\text { Daytime asthma } \\
\text { Daytime cough } \\
\text { Nocturnal symptoms } \\
\text { Asthma at the clinic }\end{array}$ & $\begin{array}{l}1.77 \\
1.94 \\
1.44 \\
0.90 \\
3.71 \\
2 \cdot 32\end{array}$ & $\begin{array}{l}(0 \cdot 63) \\
(0 \cdot 70) \\
(0 \cdot 66) \\
(0 \cdot 73) \\
(0 \cdot 98) \\
(0 \cdot 48)\end{array}$ & $\begin{array}{l}1 \cdot 78 \\
1.91 \\
1.44 \\
0.93 \\
3.69 \\
2 \cdot 32\end{array}$ & $\begin{array}{l}(0 \cdot 64) \\
(0 \cdot 70) \\
(0 \cdot 68) \\
(0 \cdot 73) \\
(1 \cdot 00) \\
(0 \cdot 48)\end{array}$ & $\begin{array}{l}-0.36 \\
-0.27 \\
-0.25 \\
-0.27 \\
-0.63 \\
-0.36\end{array}$ & $\begin{array}{l}(0 \cdot 12)^{* *} \\
(0 \cdot 13)^{* *} \\
(0 \cdot 09)^{* *} \\
(0 \cdot 08)^{* * *} \\
(0 \cdot 20)^{* * *} \\
(0 \cdot 14)^{*}\end{array}$ & $\begin{array}{l}-0.52 \\
-0.20 \\
-0.25 \\
-0.25 \\
-0.72 \\
-0.54\end{array}$ & $\begin{array}{l}(0 \cdot 13)^{* * *} \\
(0 \cdot 11) \\
(0 \cdot 09)^{*} \\
(0 \cdot 12) \\
(0 \cdot 20)^{* *} \\
(0 \cdot 15)^{* *}\end{array}$ \\
\hline $\begin{array}{l}\text { Bronchodilator use } \\
\text { Night-time } \beta_{2} \text { use } \\
\text { Daytime } \beta_{2} \text { use }\end{array}$ & $\begin{array}{l}2 \cdot 40 \\
5 \cdot 84\end{array}$ & $\begin{array}{l}(1 \cdot 84) \\
(2 \cdot 70)\end{array}$ & $\begin{array}{l}2 \cdot 47 \\
5.65\end{array}$ & $\begin{array}{l}(1 \cdot 88) \\
(2 \cdot 55)\end{array}$ & $\begin{array}{l}-0.55 \\
-0.43\end{array}$ & $\begin{array}{l}(0 \cdot 28)^{*} \\
(0 \cdot 27)\end{array}$ & $\begin{array}{l}-0.62 \\
-0.45\end{array}$ & $\begin{array}{l}(0 \cdot 23)^{* *} \\
(0 \cdot 26)\end{array}$ \\
\hline $\begin{array}{l}\text { Lung function } \\
\text { Morning PEFR (1/min) } \\
\text { Afternoon PEFR (1/min) } \\
\text { Evening PEFR (1/min) } \\
\text { Clinic FEV }(\text { litres }) \\
\text { Clinic FVC (litres) } \\
\text { Clinic PEFR }(1 / \mathrm{min})\end{array}$ & $\begin{array}{l}328 \cdot 4 \\
370 \cdot 4 \\
357 \cdot 7 \\
2 \cdot 53 \\
3 \cdot 69 \\
390 \cdot 5\end{array}$ & $\begin{array}{c}(121 \cdot 0) \\
(117 \cdot 7) \\
(118 \cdot 5) \\
(0 \cdot 94) \\
(1 \cdot 18) \\
(151 \cdot 4)\end{array}$ & $\begin{array}{c}323 \cdot 4 \\
369 \cdot 4 \\
353 \cdot 0 \\
2 \cdot 55 \\
3 \cdot 72 \\
390 \cdot 2\end{array}$ & $\begin{array}{c}(120 \cdot 3) \\
(118 \cdot 5) \\
(118 \cdot 1) \\
(0 \cdot 97) \\
(1 \cdot 20) \\
(153 \cdot 5)\end{array}$ & $\begin{array}{l}+4.9 \\
+6.7 \\
+8.7 \\
+0.03 \\
-0.08 \\
+20.3\end{array}$ & $\begin{array}{l}(5 \cdot 4) \\
(5 \cdot 6) \\
(5 \cdot 9) \\
(0 \cdot 10) \\
(0 \cdot 12) \\
(13 \cdot 0)\end{array}$ & $\begin{array}{l}+6 \cdot 3 \\
+6 \cdot 0 \\
+3 \cdot 3 \\
+0 \cdot 01 \\
+0 \cdot 04 \\
+3 \cdot 0\end{array}$ & $\begin{array}{l}(6.3) \\
(6.4) \\
(6.4) \\
(0.11) \\
(0.12) \\
(17.2)\end{array}$ \\
\hline
\end{tabular}

$\mathrm{PEFR}=$ peak expiratory flow rate; $\mathrm{FEV}_{1}=$ forced expiratory volume in one second; $\mathrm{FVC}=$ forced ventilatory capacity. $\dagger$ Negative differences for symptom scores and inhaled bronchodilator use, and positive differences for lung function indicate a greater improvement with nedocromil sodium treatment.

${ }^{*} \mathrm{p}<0.05 ;{ }^{* *} \mathrm{p}<0.01 ;{ }^{* * *} \mathrm{p}<0.001$ (all in favour of nedocromil sodium) 
Table 3 Patient and clinician opinions of treatments

\begin{tabular}{|c|c|c|c|c|}
\hline & \multicolumn{2}{|c|}{$\begin{array}{l}\text { Opinion of treatment effectiveness } \\
\text { (very/moderately effective) }\end{array}$} & \multicolumn{2}{|c|}{ More effective treatment period } \\
\hline & Patient & Clinician & Patient & Clinician \\
\hline Nedocromil sodium & 20 & 18 & 20 & 22 \\
\hline Placebo & 11 & 5 & 5 & 2 \\
\hline No preference* & - & - & 3 & 4 \\
\hline Significance & $\mathrm{p}<0.01$ & $p<0.001$ & $p<0.01$ & $p<0.01$ \\
\hline
\end{tabular}

* "Preference" was not an option for overall opinion of treatment. All significant differences in favour of nedocromil sodium. cough (nedocromil sodium) and nausea (placebo and nedocromil sodium). Three patients who completed both courses of treatment reported chest tightness and wheeze (placebo) and nausea (nedocromil sodium).

\section{Discussion}

Nedocromil sodium produced clinically and statistically significant improvements in nocturnal asthma symptoms and bronchodilator use compared with placebo. Daytime symptoms were significantly improved although the effect was less marked. Changes in lung function were not significantly different between treatments. Assessment of asthma severity indicated a clinical improvement with nedocromil sodium. These observations were in agreement with the opinions of the patients and clinicians. Despite the crossover design of the study, the expressed preference for nedocromil sodium was seemingly not due to unblinding since, although nausea was reported by two patients treated with nedocromil sodium and one treated with placebo, none commented on treatment taste.

. The BTS guidelines ${ }^{7}$ recommend the use of nedocromil sodium, sodium cromoglycate, or up to $800 \mu \mathrm{g}$ inhaled steriods daily when nocturnal symptoms are present. During the baseline period nocturnal symptoms were evident despite the fact that more than half the patients were taking inhaled steroids (mean daily dose $719 \mu \mathrm{g}$ ), and most were receiving a therapeutic dose of oral bronchodilator treatment. A review of individual opinion data indicated that patients considered nedocromil sodium to be effective irrespective of concurrent inhaled steroid treatment. This suggests that a therapeutic trial of nedocromil sodium would be beneficial in patients with nocturnal asthma symptoms, irrespective of current treatment.

1 MacDonald JB. Nocturnal asthma. What happens to the airways at night? $B M \mathcal{F} 1992 ; 304: 998-9$

2 Turner-Warwick $M$. Nocturnal asthma: a study in general practice. fR Coll Gen Pract 1989;39:239-43.

3 Edwards AM, Stevens MT. The clinical efficacy of inhaled nedocromil sodium (Tilade) in the treatment of asthma. Eur Respir f 1993;6:35-41.

4 Martin RJ, Cicutto LC, Smith HR, Ballard RD, Szefler J. Airways inflammation in nocturnal asthma. Am Rev Respir Airways inflammation
Dis 1991;143:351-7.

5 Manolitsas ND, Trigg C, McAulay A, Norton A, Wang J, Davies RJ. Comparison of the effects of treatment with nedocromil sodium and salbutamol on bronchial mucosal inflammation in asthma. Eur Respir $\mathcal{F}$ 1993;6(Suppl 17): $481 \mathrm{~S}$

6 Koch GG. The use of non-parametric methods in the statistical analysis of the two-period changeover design. Biometrics 1972;28:577-84.

7 British Thoracic Society. Guidelines on the manangement of asthma. Thorax 1993;48(Supplement):1-24. 